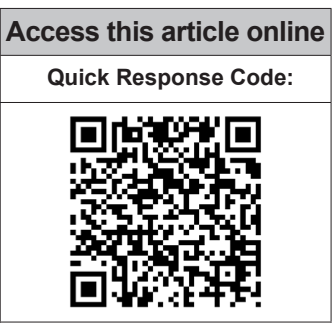

Website:

www.jponline.org

DOI:

10.4103/0974-2727.236111
Department of Pathology, Seth GS Medical College and KEM Hospital, Acharya Donde Marg, Mumbai, Maharashtra, India

Address for correspondence: Dr. Manjusha Karegar, Department of Pathology, Seth GS Medical College and K. E. M Hospital, Acharya Donde Marg, Parel, Mumbai - 400 012,

Maharashtra, India.

E-mail: manjusha.

karegar@gmail.com

Submission: 20-03-2016 Accepted: 30-09-2016

\title{
Cytologic diagnosis of unusual, large multiple cutaneous myxomas in a case of Carney complex
}

\author{
Manjusha Karegar, Mrinal Sarwate, Kanchan Kothari, Amey Rojekar, Leena Naik
}

\section{Abstract:}

Cutaneous myxomas are rare benign neoplasms which are frequently associated with Carney complex (CNC). Although more than 500 cases of CNC are reported, there is no literature on cytologic diagnosis of Cutaneous myxomas. An 18-year-old male, with no significant family history, presented with multiple cutaneous swellings, largest measuring $15 \mathrm{~cm}$ on the right cheek. He also had spotty skin pigmentations, raised adrenocorticotropic hormone levels and recurrent cardiac myxomas. Fine-needle aspiration cytology from the right cheek and suprapubic swellings revealed paucicellular smears with abundant myxoid material in the background, admixed with fragments of spindle and stellate cells with bland nuclear morphology, and vascular proliferation in few fragments. There was no mitosis, necrosis, or any epithelial element. Hence, diagnosis of cutaneous myxomas in CNC was made which was confirmed on histopathology. This is the first report of cytologic diagnosis of multiple cutaneous myxomas in CNC and the largest cutaneous myxoma reported in literature.

Key words:

Carney complex, cutaneous myxoma, fine-needle aspiration cytology diagnosis

\section{Introduction}

C utaneous myxomas are rare benign myxoid neoplasms, frequently seen in association with Carney complex (CNC) which is an autosomal dominant disorder and characterized by myxomas, spotty pigmentation, endocrine over activity, ${ }^{[1]}$ and mutations in the PRKAR1A gene. ${ }^{[2]}$

Even though more than 500 cases of $\mathrm{CNC}$ have been reported, there are no reports of fine-needle aspiration cytology (FNAC) diagnosis of cutaneous myxoma. This article presents the first largest cutaneous myxoma in CNC diagnosed on FNAC.

\section{Case Report}

An 18-year-old male presented with multiple painless cutaneous swellings over the right cheek, chin, eyelid, and suprapubic region. The swelling on the right cheek was recurrent and present since 4 years. He had a history of recurrent cardiac (left atrial and right ventricular) myxomas, operated twice for the same. He also

This is an open access journal, and articles are distributed under the terms of the Creative Commons Attribution-NonCommercial-ShareAlike 4.0 License, which allows others to remix, tweak, and build upon the work non-commercially, as long as appropriate credit is given and the new creations are licensed under the identical terms.

For reprints contact: reprints@medknow.com had an episode of cerebrovascular accident. There was no significant family history.

On examination, the swelling on right cheek $(15 \times 8 \times 6 \mathrm{~cm})$ was firm, non tender, mobile $\&$ free from underlying structures [Figure 1a]. Overlying skin surface was nodular and focally ulcerated. The other swellings on the right eyelid [Figure 1b], chin and suprapubic region were $0.5,2.0$, and $3.5 \mathrm{~cm}$, respectively. There was a small-pigmented lesion on inner canthus of the right eye, multiple pigmented macules over the left shin, and multiple nevi over legs and back. He also had vitiligo on prepuce. Endocrine workup of the patient revealed raised adrenocorticotropic hormone (ACTH) levels of $48.5 \mathrm{pg} / \mathrm{m}$.

Cytologic examination

FNAC with multiple passes was performed from the right cheek and suprapubic swellings with 23 gauge needle, with nonaspiration technique. The aspirate was thick, viscous, stringy, and gelatinous. Smears were prepared and stained with both Giemsa and Papanicolaou stain.

The smears were paucicellular and revealed abundant myxoid material in the background which stained magenta with Giemsa and pale

How to cite this article: Karegar $M$, Sarwate $M$, Kothari K, Rojekar A, Naik L. Cytologic diagnosis of unusual, large multiple cutaneous myxomas in a case of Carney complex. J Lab Physicians 2018;10:354-6. 
blue green with Papanicolaou stain. It was admixed with hypocellular fragments of spindle and stellate cells with oval to spindle nuclei having evenly dispersed, fine chromatin, thin nuclear membrane, and inconspicuous nucleoli. Focal mild nuclear pleomorphism was noted. Mitosis and necrosis were absent. Few fragments showed thin delicate vascular cores. Epithelial structures were not seen. There were no cytologic features of malignancy [Figure 2].

Based on the cytomorphological features, subcutaneous superficial location of the lesions and the clinical background of recurrent cardiac myxomas, complications of cardiac myxoma in the form of stroke, cutaneous pigmentations, and endocrine abnormalities in the form of raised $\mathrm{ACTH}$, cytologic diagnosis of multiple cutaneous myxomas was given in a clinical case of CNC. In view of the unusually large size and for cosmetic reasons, the cheek mass and eyelid lesion were excised.

On gross examination, the cheek mass measured $15 \mathrm{~cm} \times 13 \mathrm{~cm} \times 6 \mathrm{~cm}$. Overlying skin was focally ulcerated. On cut-surface, it was well-circumscribed, nodular, solid, gelatinous with few cystic and hemorrhagic areas [Figure 3].

Microscopic examination revealed a tumor in the dermis and subcutaneous plane which was composed of multiple hypocellular nodules with abundant myxoid stroma and spindle to stellate cells within it. Focally, increased cellularity was seen. The cells had bland nuclear morphology and lacked cytological atypia. Mitosis and necrosis were absent. Focal areas of capillary proliferation, epithelial proliferation, and cystic changes were also seen. The eyelid lesion also showed similar morphology. Thus, the diagnosis of multiple cutaneous myxomas was confirmed [Figure 3].

\section{Discussion}

Cutaneous myxomas are reported in $30 \%-55 \%$ of $\mathrm{CNC}^{\left[{ }^{[3]}\right.}$ They are asymptomatic and appear as small papules, sessile finger-like or pedunculated lesions. ${ }^{[4]}$ They are usually small in size and rarely exceed $1 \mathrm{~cm}$ in diameter.

They often affect the eyelids, ears, and nipples but may also be seen on other areas of the face, ears, trunk, and perineum. ${ }^{[5]}$

In 1988, Allen et al. reported cutaneous tumors as superficial angiomyxomas in 28 patients aged $4-78$ years that were histologically similar to cutaneous myxomas of $\mathrm{CNC}$ but had no evidence of the complex. Most of the tumors measured $0.5-9 \mathrm{~cm}$, on the head, neck, trunk, or lower extremity. ${ }^{[6]}$ The largest superficial angiomyxoma reported till date was measured $10 \mathrm{~cm}$ in its maximum dimension and was located in the thigh. ${ }^{[7]}$

Literature on FNAC of myxoid lesions is principally related to soft tissue tumors. ${ }^{[8,9]}$ To the best of our knowledge, there is a single case report of FNAC of superficial angiomyxoma ${ }^{[10]}$ and we have not found any cytological study about cutaneous myxomas.

The most common myxoid lesion in the cheek region to be ruled out is pleomorphic adenoma, which in addition to the chondromyxoid stroma, shows myoepithelial and ductal cells

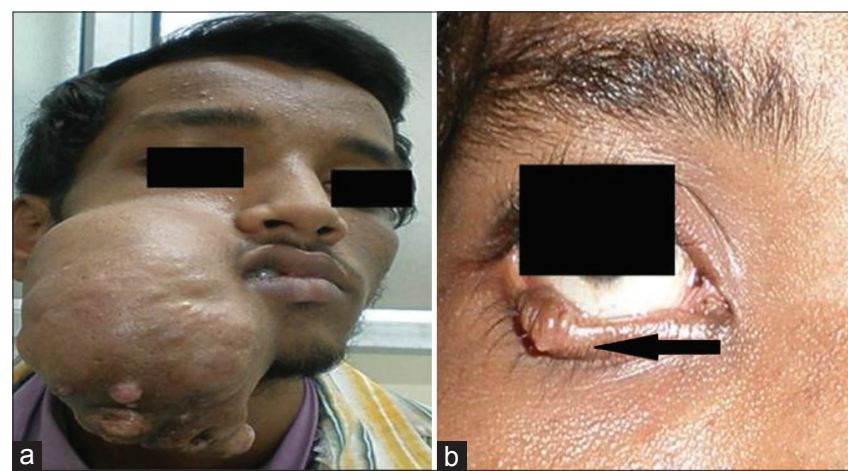

Figure 1: (a) Large nodular and focally ulcerated swelling on the right cheek $(15 \mathrm{~cm} \times 8 \mathrm{~cm} \times 6 \mathrm{~cm})$ (b) swelling on eyelid

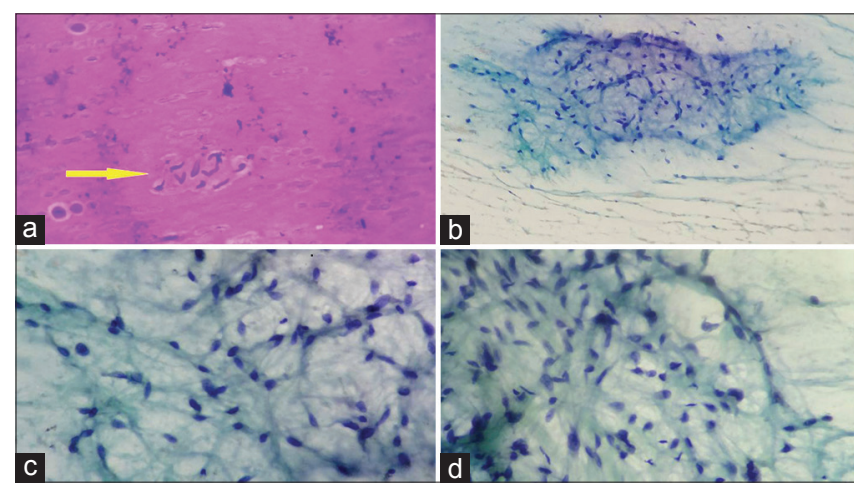

Figure 2: $(a$ and $b)$ Hypocellular fragments of spindle and stellate cells with oval to spindle nuclei in abundant myxoid material in background

(Giemsa, ×40, Papanicolaou, ×10) (c and d) Oval to spindle nuclei have evenly dispersed, fine chromatin, thin nuclear membrane, and inconspicuous nucleoli with focal mild nuclear pleomorphism and thin delicate vascular cores (Papanicolaou, $\times 40$ )

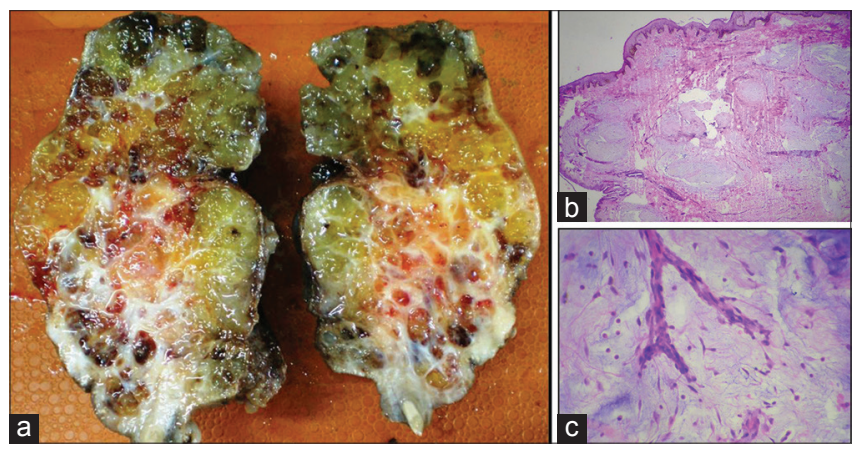

Figure 3: (a) Cut surface of cheek mass shows circumscribed, nodular, solid-cystic mass showing gelatinous and hemorrhagic areas. (b) Tumor in the dermis and subcutaneous plane is composed of multiple hypocellular nodules with abundant myxoid stroma and spindle to stellate cells within it. Focally increased cellularity is seen $(H$ and $E, \times 4)(c)$ small proliferating blood vessels with stellate cells and myxoid stroma in the background $(\mathrm{H}$ and $\mathrm{E}, \times 40)$

in various proportions. The stroma is mixed intimately with the cellular elements. Other rare lesions in the differential diagnosis are myxoid benign neural tumors, which show spindle cells with elongated classical wavy nuclei and low-grade myxoid soft tissue sarcoma, which are deep seated, and show uniform fibroblasts such as spindle cells with mild nuclear atypia without any vascular component. 
Our patient thus had multiple cutaneous myxomas on the cheek, chin, eyelids, and suprapubic region, with recurrence of cheek myxoma. The patient also had recurrent cardiac myxomas and complication of cardiac myxoma in form of stroke. He had cutaneous pigmentations and endocrine abnormalities in the form of raised ACTH. Mutations in the PRKAR1A gene could not be demonstrated due to the nonaffordability of the patient. On follow-up, the patient developed an ear myxoma, which was excised and the diagnosis confirmed on histology.

In conclusion, this is the first report of cytologic diagnosis of multiple cutaneous myxomas in CNC and this is the largest cutaneous myxoma reported in literature.

\section{Declaration of patient consent}

The authors certify that they have obtained all appropriate patient consent forms. In the form the patient(s) has/have given his/her/their consent for his/her/their images and other clinical information to be reported in the journal. The patients understand that their names and initials will not be published and due efforts will be made to conceal their identity, but anonymity cannot be guaranteed.

Financial support and sponsorship

Nil.

Conflicts of interest

There are no conflicts of interest.

\section{References}

1. Carney JA, Gordon H, Carpenter PC, Shenoy BV, Go VL. The complex of myxomas, spotty pigmentation, and endocrine overactivity. Medicine (Baltimore) 1985;64:270-83.

2. Casey M, Vaughan CJ, He J, Hatcher CJ, Winter JM, WeremowiczS, et al. Mutations in the protein kinase A R1alpha regulatory subunit cause familial cardiac myxomas and Carney complex. J Clin Invest 2000;106:R31-8.

3. Bertherat J, Horvath A, Groussin L, Grabar S, Boikos S, Cazabat L, et al. Mutations in regulatory subunit type $1 \mathrm{~A}$ of cyclic adenosine 5'-monophosphate-dependent protein kinase (PRKAR1A): Phenotype analysis in 353 patients and 80 different genotypes. J Clin Endocrinol Metab 2009;94:2085-91.

4. Mateus C, Palangié A, Franck N, Groussin L, Bertagna X, Avril MF, et al. Heterogeneity of skin manifestations in patients with Carney complex. J Am Acad Dermatol 2008;59:801-10.

5. Stratakis CA, Kirschner LS, Carney JA. Clinical and molecular features of the Carney complex: Diagnostic criteria and recommendations for patient evaluation. J Clin Endocrinol Metab 2001;86:4041-6.

6. Allen PW, Dymock RB, MacCormac LB. Superficial angiomyxomas with and without epithelial components. Report of 30 tumors in 28 patients. Am J Surg Pathol 1988;12:519-30.

7. Yamamoto K, Kondo A, Iwashita K, Umezawa Y, Ohta Y, Matsuyama T. A case of superficial angiomyxoma. Tokai J Exp Clin Med 2006;31:43-5.

8. Wakely PE Jr. Myxomatous soft tissue tumors: Correlation of cytopathology and histopathology. Ann Diagn Pathol 1999;3:227-42.

9. Wakely PE Jr., Bos GD, Mayerson J. The cytopathology of soft tissue mxyomas: Ganglia, juxta-articular myxoid lesions, and intramuscular myxoma. Am J Clin Pathol 2005;123:858-65.

10. Izquierdo FM, Martin L, Burgos F, Lacruz C. Fine-needle aspiration cytology of superficial angiomyxoma (myxoid perifollicular fibroma): Report of a case. Diagn Cytopathol 1995;13:247-51. 